Research Article

\title{
Phenol Red Adsorption from Aqueous Solution on the Modified Bentonite
}

\author{
Nguyen Le My Linh,, ${ }^{1}$ Tran Duong, ${ }^{1}$ Hoang Van Duc, ${ }^{1}$ Nguyen Thi Anh Thu, \\ Pham Khac Lieu, ${ }^{2}$ Nguyen Van Hung $\mathbb{D}^{3},{ }^{3}$ Le Thi Hoa, ${ }^{4}$ and Dinh Quang Khieu $\mathbb{D}^{4}$ \\ ${ }^{1}$ University of Education, Hue University, Hue 49000, Vietnam \\ ${ }^{2}$ Hue University, Hue 49000, Vietnam \\ ${ }^{3}$ Center for Chemistry Analysis, Dong Thap University, Cao Lãnh 81000, Vietnam \\ ${ }^{4}$ University of Sciences, Hue University, Hue 49000, Vietnam
}

Correspondence should be addressed to Dinh Quang Khieu; dqkhieu@hueuni.edu.vn

Received 26 April 2020; Revised 19 June 2020; Accepted 1 July 2020; Published 28 July 2020

Academic Editor: Pedro M. Mancini

Copyright (c) 2020 Nguyen Le My Linh et al. This is an open access article distributed under the Creative Commons Attribution License, which permits unrestricted use, distribution, and reproduction in any medium, provided the original work is properly cited.

\begin{abstract}
In the present work, the modified bentonites were prepared by the modification of bentonite with cetyltrimethylammonium bromide $(\mathrm{CTAB})$, both cetyltrimethylammonium bromide and hydroxy-Fe cations and both cetyltrimethylammonium bromide and hydroxy-Al cations. X-ray diffraction (XRD), thermal analysis (TG-DTA), infrared spectroscopy (FT-IR), scanning electron microscopy (SEM), and nitrogen adsorption/desorption isotherms were utilized to characterize the resultant modified bentonites. The modified bentonites were employed for the removal of phenol red dye from aqueous solution. Phenol red adsorption agreed well with the pseudo-second-order kinetic model. The equilibrium data were analyzed on the basis of various adsorption isotherm models, namely, Langmuir, Freundlich, and Dubinin-Radushkevich models. The highest monolayer adsorption capacity of phenol red at $30^{\circ} \mathrm{C}$ derived from the Langmuir equation was $166.7 \mathrm{mg} \cdot \mathrm{g}^{-1}, 125.0 \mathrm{mg} \cdot \mathrm{g}^{-1}$, and $100.0 \mathrm{mg} \cdot \mathrm{g}^{-1}$ for CTAB-bentonite, $\mathrm{Al}-\mathrm{CTAB}$-bentonite, and $\mathrm{Fe}-\mathrm{CTAB}$-bentonite, respectively. Different thermodynamic parameters were calculated, and it was concluded that the adsorption was spontaneous $\left(\Delta G^{\circ}<0\right)$ and endothermic $\left(\Delta H^{\circ}>0\right)$, with increased entropy $\left(\Delta S^{\circ}>0\right)$ in all the investigated temperature ranges.
\end{abstract}

\section{Introduction}

In recent years, dyes are used widely in many industries such as textiles, paper, printing, and cosmetics. Besides the economic benefits, these industries release a large amount of highly toxic dyes in wastewater every year, most of which have negative effects on human and animal health. Various techniques such as adsorption [1-4], catalysis [5, 6], electrochemical oxidation [7], ozonation [8], membrane filtration [9], biological treatment [10], and enzymes [11] have been used to remove the dye components from polluted wastewater. Phenol red is a fabric dye and if we are exposed to the dye, it will affect the respiratory system and human skin [12]. Therefore, many research studies focus on the preparation of adsorbents or redox agents for the removal of phenol red. Actually, oxidation and adsorption are the two main methods for the removal of phenol red. In recent reports on the first method, advanced oxidation processes have received the most attention [14-16]. For the second one, Abdullah et al. [13] prepared composite silica-filled ENR/PVC beads for phenol red adsorption. The results showed that the maximal adsorption capacity is $2.67 \mathrm{mg} \cdot \mathrm{g}^{-1}$. Iqbal et al. [14] found that the phenol red adsorption process on activated carbon materials was spontaneous with increasing entropy. The kinetic and thermodynamic studies of the phenol red absorption on bottom ash and deoiled soya were investigated very specifically by Mittal et al. [12]. The highest monolayer adsorption capacity has been obtained for the phenol red-bottom ash system $\left(2.6 \times 10^{-5} \cdot \mathrm{mol} \cdot \mathrm{g}^{-1}\right)$ at $50^{\circ} \mathrm{C}$. Recently, many researchers have been using natural 
materials like bentonite and modified bentonite for the removal of phenol and other dyes [15-26]. Organobentonites have been formed by introducing organic cations into bentonite layers. The purpose of organic bentonite synthesis is to create hydrophobic materials from hydrophilic form, so that they can be used as sorbents for hydrophobic organic compounds. Meanwhile, the inorganic bentonites with hydrophilic surfaces are suitable for adsorbing heavy metals. Thus, simultaneously inserting both metal ions and organic substances into bentonite, a new material is created named inorganic-organic bentonite. Because of the novel properties of the inorganic-organic bentonite, their structural characteristics have drawn great interest in recent years. Intercalation methods, intercalation agents, and bentonite/organic compound/inorganic compound ratios will affect the structures of inorganic-organic bentonite. To date, few studies have clarified the adsorption of the dyes onto organic bentonite and inorganic-organic bentonite.

In the work, the synthesis of CTAB-bentonite, Al$\mathrm{CTAB}$-bentonite, and $\mathrm{Fe}-\mathrm{CTAB}-$ bentonite and phenol red adsorption are demonstrated. The kinetics, isotherms, thermodynamics, and the mechanism of phenol red adsorption process on modified bentonite materials are addressed.

\section{Experimental}

2.1. Materials. Bentonite supplied from TT-Hue Mineral Company, Vietnam, was purified (denoted as $\mathrm{B}$ ) with chemical composition $\mathrm{SiO}_{2}$ 69.1, $\mathrm{Al}_{2} \mathrm{O}_{3}$ 18.7, $\mathrm{Fe}_{2} \mathrm{O}_{3}$ 4.4, $\mathrm{TiO}_{2}$ 0.37, $\mathrm{MgO} 4.19, \mathrm{CaO} 2.93, \mathrm{~K}_{2} \mathrm{O} 0.25$, and $\mathrm{Na}_{2} \mathrm{O} 0.07$ (mass $\%)$. Cetyltrimethylammonium bromide (CTAB) (Merck), phenol red $\left(\mathrm{C}_{19} \mathrm{H}_{14} \mathrm{O}_{5} \mathrm{~S}\right.$, Merck), aluminum chloride hexahydrate $\left(\mathrm{AlCl}_{3} \cdot 6 \mathrm{H}_{2} \mathrm{O}\right.$, Guangzhou, 99\%), ferric nitrate nonahydrate $\left(\mathrm{Fe}\left(\mathrm{NO}_{3}\right)_{3} .9 \mathrm{H}_{2} \mathrm{O}\right.$, Guangzhou, $\left.99 \%\right)$, and silver nitrate $\left(\mathrm{AgNO}_{3}\right.$, Guangzhou) were used in this study.

2.2. Preparation of CTAB-Modified Bentonite and Fe-CTABModified and Al-CTAB-Modified Bentonites. The CTAB bentonite was synthesized as follows: $1.0 \mathrm{~g}$ of the purified bentonite (B) in $100 \mathrm{~mL}$ distilled water was stirred for $1 \mathrm{~h}$. The $100 \mathrm{~mL}$ solution containing $0.8 \mathrm{~g}$ of CTAB was dissolved completely by vigorous stirring for $1 \mathrm{~h}$ and then was dropped slowly into the bentonite dispersion. The mixture was stirred with a magnetic stirrer for $4 \mathrm{~h}$ at $50^{\circ} \mathrm{C}$. The obtained mixture was kept at $60^{\circ} \mathrm{C}$ for $20 \mathrm{~h}$. The modified bentonite was washed many times with deionized water, dried at $100^{\circ} \mathrm{C}$ for $5 \mathrm{~h}$, and then ground into the powder. The obtained CTABbentonite was denoted as $\mathrm{CB}$.

The synthesis of $\mathrm{Fe}-\mathrm{CTAB}-$ bentonite was carried by the following steps. Firstly, the Fe pillaring solution was prepared from the mixture of $100 \mathrm{~mL} 0.1 \mathrm{M} \mathrm{Fe}\left(\mathrm{NO}_{3}\right)_{3} .9 \mathrm{H}_{2} \mathrm{O}$ solution, and $30 \mathrm{~mL} \quad 0.1 \mathrm{M} N \mathrm{NaOH} \quad\left(\mathrm{OH}^{-} / \mathrm{Fe}^{3+}\right.$ molar ratio $=0.3)$. Then, it was stirred for $2 \mathrm{~h}$ and kept at room temperature for $24 \mathrm{~h}$. Secondly, the $1 \% \mathrm{CB}$ suspension was prepared by dispersing $1 \mathrm{~g}$ of $\mathrm{CB}$ in $1 \mathrm{~L}$ of deionized water. Then, the Fe pillaring solution prepared above was dropped slowly into the CB suspension. The mixture was stirred for $24 \mathrm{~h}$ at room temperature. The resultant solid was separated by centrifugation and dried at $100^{\circ} \mathrm{C}$ for $10 \mathrm{~h}$ to obtain the $\mathrm{Fe}-\mathrm{CTAB}-$ bentonite (denoted as $\mathrm{FeCB}$ ).

The Al-CTAB-bentonite was synthesized in the same manner, except for the pillaring solution which was prepared by adding drop by drop $200 \mathrm{~mL}$ of $0.1 \mathrm{M} \mathrm{NaOH}$ solution to $100 \mathrm{~mL} 0.1 \mathrm{M} \mathrm{AlCl}_{3}$ solution. This resultant pillaring bentonite suspension was stirred for $7 \mathrm{~h}$ at $70^{\circ} \mathrm{C}$ and then kept at room temperature for $24 \mathrm{~h}$. The Al-CTAB-bentonite solid was separated by centrifugation, dried at $100^{\circ} \mathrm{C}$, and denoted as $\mathrm{AlCB}$.

2.3. Characterization. The purified and modified bentonites were studied by X-ray diffraction (XRD, D8-Advance Brucker, Germany with $\left.\lambda_{\mathrm{CuK} \alpha}=1.5406 \AA\right)$. The thermal curves of the products were obtained in a DTG-60H (Shimadzu). Fourier transform infrared spectra (FT-IR) using $\mathrm{KBr}$ pressed disk technique were gained on SHIMADZU FT-IR 8010M. Nitrogen adsorption-desorption isotherms were measured on Tri Star 3000. The samples were outgassed for $5 \mathrm{~h}$ at $250^{\circ} \mathrm{C}$ in the degas port of the instrument. The specific surface areas were calculated using the BET model. SEM ima4ges were taken by scanning electron microscopy (Hitachi, S-4500). The point of zero charge values $\left(\mathrm{pH}_{\mathrm{PZC}}\right)$ of the samples were calculated by the $\mathrm{pH}$ drift method.

\subsection{Adsorption Experiments}

2.4.1. Effect of $p H$. The phenol red adsorption of modified bentonites was carried out in a batch system. An exact amount $(0.05 \mathrm{~g})$ of modified bentonite was placed into the $100 \mathrm{~mL}$ flask containing $50 \mathrm{~mL}$ of $100 \mathrm{mg} \cdot \mathrm{L}^{-1}$ phenol red solution. The $\mathrm{pH}$ solution was adjusted from 2 to 10 by adding amounts of $0.01 \mathrm{M} \mathrm{NaOH}$ or $0.01 \mathrm{M} \mathrm{HCl}$, and the flasks were stirred by a magnetic stirrer for $6 \mathrm{~h}$ at room temperature $\left(30^{\circ} \mathrm{C}\right)$ to reach equilibrium. After equilibrium, the supernatant was collected, and the concentration of phenol red was analyzed by UV-Vis method at $\lambda_{\max }=435 \mathrm{~nm}$.

The adsorption uptake of phenol red by the adsorbent was calculated by using

$$
q_{t}=\frac{C_{o}-C_{t}}{m} . V
$$

where $q_{\mathrm{t}}$ is the adsorption uptake of phenol red on the adsorbent at time $t, C_{\mathrm{o}}$ and $C_{\mathrm{t}}\left(\mathrm{mg} \cdot \mathrm{L}^{-1}\right)$ are the phenol red concentration at the initial time and a certain time, $t$, respectively, $V(L)$ is the volume of phenol red solution, and $m$ $(g)$ is the mass of the adsorbent.

\subsubsection{Adsorption Kinetics and Thermodynamics Studies.} A measured amount (0.2 grams) of the adsorbent $(B, C B$, $\mathrm{AlCB}$, or $\mathrm{FeCB}$ ) was added to $250 \mathrm{~mL}$ of $100 \mathrm{mg} \cdot \mathrm{L}^{-1}$ phenol red at $\mathrm{pH}$ 3.0. The mixture was stirred by a magnetic stirrer at different temperatures $\left(20,30,40\right.$, and $\left.50^{\circ} \mathrm{C}\right)$. This suspension was then centrifuged after a particular time interval, 
and the phenol red concentration in the supernatant was measured by UV-Vis spectroscopy.

Kinetic data were applied to pseudo-first/second-order kinetic models [27]. The pseudo-first-order model is given by

$$
\ln \left(q_{e}-q_{t}\right)=\ln \left(q_{e}-k_{1}\right) \cdot t
$$

where $q_{e}$ and $q_{t}$ are the phenol red uptake of adsorbent at equilibrium, and at time $t\left(\mathrm{mg}^{-1} \mathrm{~g}^{-1}\right), k_{1}$ is the first-order rate constant $\left(\mathrm{min}^{-1}\right)$.

The pseudo-second-order kinetic model is given by

$$
\frac{t}{q_{t}}=\frac{1}{k_{2} q_{e}^{2}}+\frac{1}{q_{e}} . t
$$

where $k_{2}$ is the rate constant of the pseudo-second-order kinetic model $\left(\mathrm{g} \cdot \mathrm{mol}^{-1} \cdot \mathrm{min}^{-1}\right)$.

2.4.3. Equilibrium Adsorption Studies. In equilibrium experiments, $0.05 \mathrm{~g}$ of adsorbent was added to $50 \mathrm{~mL}$ of phenol red solution with different concentrations $(20,40,50,60,70$, 80,90 , and $100 \mathrm{mg} \cdot \mathrm{L}^{-1}$ ) at initial $\mathrm{pH}$ 3.0. The equilibrium adsorption experiments were performed for $24 \mathrm{~h}$ at different temperatures of $10^{\circ} \mathrm{C}, 20^{\circ} \mathrm{C}$, and $30^{\circ} \mathrm{C}$.

Langmuir, Freundlich, and Dubinin-Radushkevich isotherm models were employed to analyze the equilibrium adsorption data. The Langmuir isotherm [27] can be expressed as

$$
\frac{C_{e}}{q_{e}}=\frac{C_{e}}{q_{m}}+\frac{1}{K_{L} \cdot q_{m}},
$$

where $C_{e}$ is the equilibrium concentration of adsorbate in the solution (mg.g $\left.{ }^{-1}\right), q_{m}$ is the monolayer maximum adsorption uptake of the adsorbent $\left(\mathrm{mg} \cdot \mathrm{g}^{-1}\right)$, and $K_{L}$ is the Langmuir constant $\left(\mathrm{L} \cdot \mathrm{mg}^{-1}\right)$ which is related to the energy of adsorption, respectively. The other parameters were described above. $q_{m}$ and $K_{L}$ can be calculated from the intercept and slope of the linear plot of $C_{e} / q_{e}$ versus $C_{e}$.

Additionally, the essential features of the Langmuir isotherm can be expressed in terms of a dimensionless constant called separation factor $\left(R_{L}\right.$, also called equilibrium parameter) which is defined by the following expression:

$$
R_{L}=\frac{1}{1+K_{L} C_{0}},
$$

where $C_{o}\left(\mathrm{mg} \cdot \mathrm{L}^{-1}\right)$ is the initial dye concentration and $K_{L}$ $\left(\mathrm{L} \cdot \mathrm{mg}^{-1}\right)$ is the Langmuir constant.

Freundlich equation [27] is given as

$$
\ln q_{e}=\ln K_{F}+\frac{1}{n} \cdot \ln C_{e}
$$

where $K_{\mathrm{F}}$ and $n$ are the Freundlich constants. These constants can be calculated from the slope and intercept of the linear plot of $\ln q_{e}$ versus $\ln C_{e}$.

The linear form of the Dubinin-Radushkevich isotherm [28] is given by

$$
\ln q_{e}=\ln q_{t}-\beta \varepsilon^{2}
$$

where the constant $\beta$ is related to the mean free energy $E$ $\left(\mathrm{kJ} \cdot \mathrm{mol}^{-1}\right)$ of adsorption per molecule of the adsorbate when it is moved to the surface of the solid from the solution $\left(\mathrm{mol}^{2} \cdot \mathrm{J}^{-2}\right)$ and $\varepsilon$ is the Polanyi potential which can be calculated by

$$
\varepsilon=\mathrm{RT} \ln \left[1+\left(\frac{1}{C_{e}}\right)\right]
$$

The mean free energy can be computed by using the following relation:

$$
E=\frac{1}{(2 \beta)^{(1 / 2)}} \text {. }
$$

The thermodynamic parameters including the standard free-energy changes of Gibbs, $\Delta G^{\circ}$, standard enthalpy changes, $\Delta H^{\circ}$, and standard entropy changes, $\Delta S^{\circ}$, were also studied to better understand the adsorption mechanism. The $\Delta G^{\circ}$ was calculated based on

$$
\begin{aligned}
\Delta G^{o} & =-\mathrm{RT} \ln K_{L} . \\
\ln K_{L} & =-\frac{\Delta G^{o}}{\mathrm{RT}}=-\frac{\Delta H^{o}}{\mathrm{RT}}+\frac{\Delta S^{o}}{R} .
\end{aligned}
$$

The values of $\Delta H^{\circ}$ and $\Delta S^{\circ}$ can be calculated from the slope and intercept of the linear plot of $\ln K_{L}$ versus $1 / T$.

\section{Results and Discussion}

3.1. Characterization of the Adsorbents. Basal spacing is one of the most important factors reflecting the structural characteristics of the modified layered clays. XRD was employed to characterize the layer structures of the intercalated bentonite in this study. The XRD patterns of $B, C B$, $\mathrm{AlCB}$, and $\mathrm{FeCB}$ are shown in Figure 1.

The purified bentonite (B) exhibits the characteristic peaks of the montmorillonite according to JCPDS No. 00003-0014. The changes of basal spacing of the modified bentonite can reflect the intercalations of CTAB, hydroxy$\mathrm{Al}$, and hydroxy-Fe cations into bentonite interlayer spaces. The bentonite $(\mathrm{B})$ had a basal spacing $\left(d_{001}\right)$ of $1.44 \mathrm{~nm}$. For the $\mathrm{CB}$, the (001) reflection was observed at a lower angle, corresponding to a larger basal spacing $d_{001}=1.81 \mathrm{~nm}$, which indicated that the CTAB intercalated into bentonite interlayer spaces. As reported by $\mathrm{Hu}$ et al. [29], the height of alkyl chain was about from 0.40 to $0.45 \mathrm{~nm}$, and the value of $1.81 \mathrm{~nm}$ approximated to the sum of the height of the two alkyl chains and the bentonite thickness $(0.96 \mathrm{~nm})$, indicating that the alkyl chains took the arrangement of a bilayer in the interlayer. For AlCB, the peak in the pattern shifted to a smaller value of $2 \theta$, and the corresponding basal spacing was $1.99 \mathrm{~nm}$, which was larger than that of $\mathrm{CB}$. This indicated that hydroxy-Al $\left(\left[\mathrm{Al}_{13} \mathrm{O}_{4}(\mathrm{OH})_{24}\left(\mathrm{H}_{2} \mathrm{O}\right)_{12}\right]^{7+}, \mathrm{Al}_{13}\right)$ could be intercalated and expand the interlayers of $\mathrm{CB}$ even when the "channels and grooves" between bentonite layers were occupied by CTAB (or $\mathrm{CTA}^{+}$cations). For FeCB, there was also change in $d_{001}$ basal spacing $\left(d_{001}=1.82 \mathrm{~nm}\right)$ indicating that polyhydroxy-Fe or polyoxo-Fe cations $\left(\left[\mathrm{Fe}_{13} \mathrm{O}_{4}(\mathrm{OH})_{24}\left(\mathrm{H}_{2} \mathrm{O}\right)_{12}\right]^{7+}\right)$ intercalated into bentonite 


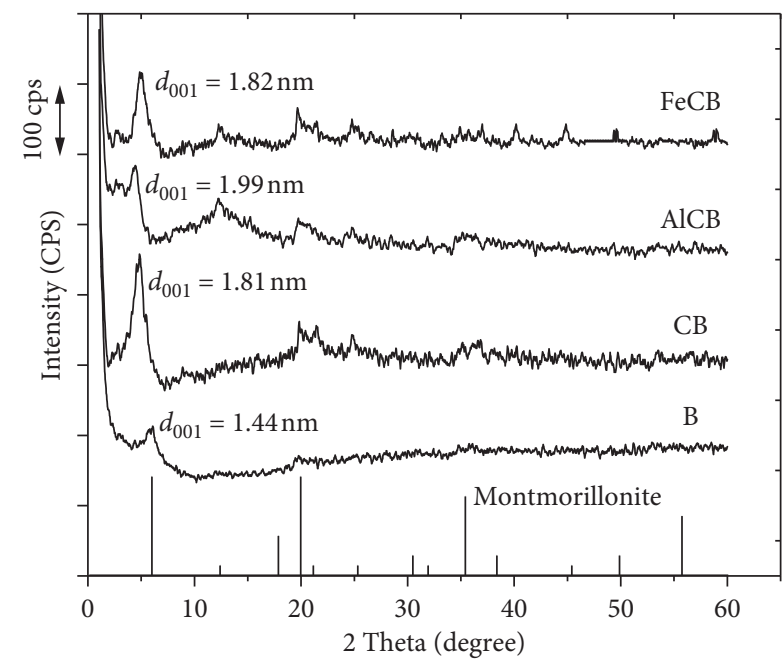

FIgURE 1: XRD patterns of B (bentonite), CB (CTAB-bentonite), AlCB (Al-CTAB bentonite), and FeCB (Al-CTAB bentonite).

interlayer spaces [30], and there was an ion exchange between the intercalated surfactant cations and the polyhydroxy-Fe or polyoxo-Fe cations. It is notable that the (001) reflections of all modified bentonites were more intensive than that of purified bentonite (B), suggesting that these materials had better crystallinity than that of $\mathrm{B}$ sample. This might explain that when inserting $\mathrm{CTA}^{+}$cations into bentonite, CTAB acted as an ion exchanger with hydrated cation localized in the interlayer spaces of bentonite and promoted the rearrangement of the clay layers (Figure 2), so the material structure obtained was highly orderly, shown in sharp reflection (001) peaks. In other words, CTAB had "assembled" small bentonite particles into larger particles with an orderly structure due to the connection between $\mathrm{CTAB}$ particles with negatively charged edges of small bentonite particles.

FT-IR has been widely used for the characterization of the modified bentonite. FT-IR spectra between 4000 and $400 \mathrm{~cm}^{-1}$ for $\mathrm{B}, \mathrm{CB}, \mathrm{AlCB}$, and $\mathrm{FeCB}$ are presented in Figure 3.

For B sample, the peak at $3414 \mathrm{~cm}^{-1}$ is related to the stretching vibration of the adsorbed water molecules [31], and the peak at $1638 \mathrm{~cm}^{-1}$ represented the deformation band $(\delta(\mathrm{O}-\mathrm{H}))$. The peak at $964 \mathrm{~cm}^{-1}$ was due to $\mathrm{Si}-\mathrm{OH}$ vibration [18], and the peak at $816 \mathrm{~cm}^{-1}$ corresponded to $\mathrm{Fe}-\mathrm{Fe}-\mathrm{OH}$ deformation vibration [32]. For organobentonite (CB), the new peaks at $2922 \mathrm{~cm}^{-1}$ and $2851 \mathrm{~cm}^{-1}$ were attributed to the antisymmetric and symmetric stretching vibrations of $-\mathrm{CH}_{2}$, respectively. The corresponding deformation modes of these groups were observed between 1470 and $1418 \mathrm{~cm}^{-1}$ [33]. The peak at $1488 \mathrm{~cm}^{-1}$ was assigned to the vibration of the quaternary amine functional group [33]. All of these vibration bands confirmed the modification of bentonite with CTAB. With the intercalation of CTAB, $\mathrm{H}_{2} \mathrm{O}$ content was reduced with the replacement of the hydrated cations by $\mathrm{CTAB}$, and the surface of bentonite was changed from hydrophilic to hydrophobic. This could be explained by a decrease in the intensity of peak at the $1635 \mathrm{~cm}^{-1}$ of the CB sample. FT-IR spectra of organic-inorganic bentonite samples displayed a doublet at $2922 \mathrm{~cm}^{-1}$ and $2851 \mathrm{~cm}^{-1}$ with lower intensity compared with that of $\mathrm{CB}$, indicating that some intercalated surfactants were exchanged by hydroxy-Al or hydroxy-Fe. For AlCB, a new peak appeared at $726 \mathrm{~cm}^{-1}$ with low intensity, and it corresponded to Al-O vibration in $\mathrm{Al}-\mathrm{OH}$, suggesting that $\mathrm{Al}_{13}$ cations were intercalated into the layers of bentonite.

TG and DTA curves of the samples are shown in Figure 4 . The TG curves of $\mathrm{B}$ and modified bentonites samples showed mass loss below $200^{\circ} \mathrm{C}$ and above $600^{\circ} \mathrm{C}$ due to the vaporization of adsorbed water or interlayer water in bentonite and the dehydroxylation of the silicate layers, respectively. A mass loss attributed to the decomposition of the organic compounds on the $\mathrm{CB}$ was observed between 200 and $600^{\circ} \mathrm{C}(11.9 \%)$. The decomposition took place in several steps, which could be seen in the DTA curve (Figure $4(\mathrm{~b})$ ). The first strong DTA peak at $289.3^{\circ} \mathrm{C}$ corresponded to the decomposition of the organic compounds presented in $\mathrm{CB}$, and the second small DTG peak at approximately $510^{\circ} \mathrm{C}$ was assigned to decompose the residuals of CTAB occluded inside capillaries of bentonite. The TG curves of AlCB and FeCB samples included the stages similar to those of $\mathrm{CB}$. However, the two later mass losses of these samples were larger than those of CB (CB: $\Delta m_{2}=11.9 \%$, $\Delta m_{3}=7.5 \%$; AlCB: $\Delta m_{2}=29.9 \%, \Delta m_{3}=9.3 \% ; \quad$ FeCB: $\left.\Delta m_{2}=15.1 \%, \Delta m_{3}=9.3 \%\right)$, suggesting that the stage in the range of the temperatures over $200^{\circ} \mathrm{C}$ could also be assigned to dehydration of hydroxy-Al or hydroxy-Fe cations.

The SEM micrographs of the materials are presented in Figure 5. The B sample consisted of small-sized clay particles and the particles presented face-face layer aggregations, which were classical arrangements for smectites. The morphology of CB consisted of clay sheets of a few micrometers in diameter, around which were smaller-sized particles, which were not observed in the original bentonite sample. The Fe-CTAB or Al-CTAB modified bentonite samples included sheets of several micrometers in size stacked on top of each other, showing that their layer structures were much clearer than those of the original $B$ sample. In addition, the $\mathrm{AlCB}$ and FeCB samples showed less face to edge interactions, increasing the interactions face to face and gave consequently a more ordered morphology. This could be explained by the interaction between CTAB particles and hydroxyl-Al cations or between CTAB particles and hydroxyl-Fe cations inserted into bentonite, between these ions and bentonite layers, leading to the arrangement of the material mainly composed of bentonite layers (face-face).

The nitrogen adsorption and desorption isotherms of the $\mathrm{B}, \mathrm{CB}, \mathrm{AlCB}$, and $\mathrm{FeCB}$ materials are shown in Figure 6. The isotherms were all of type IV in accordance with IUPAC classification. Particularly for the $\mathrm{CB}$ sample, it was found that this material hardly adsorbed $\mathrm{N}_{2}$ molecules, and the adsorption/desorption branches of $\mathrm{N}_{2}$ sorption isotherm overlapped each other. Table 1 shows that the specific surface area was strongly decreased after intercalating organic cations or both inorganic and organic cations into interlayer spaces of bentonite, from 114.44 (B) to $0.25 \mathrm{~m}^{2} \cdot \mathrm{g}^{-1}(\mathrm{CB})$, $10.07 \mathrm{~m}^{2} \cdot \mathrm{g}^{-1}(\mathrm{AlCB})$, and $16.56 \mathrm{~m}^{2} \cdot \mathrm{g}^{-1}(\mathrm{FeCB})$. This could be 

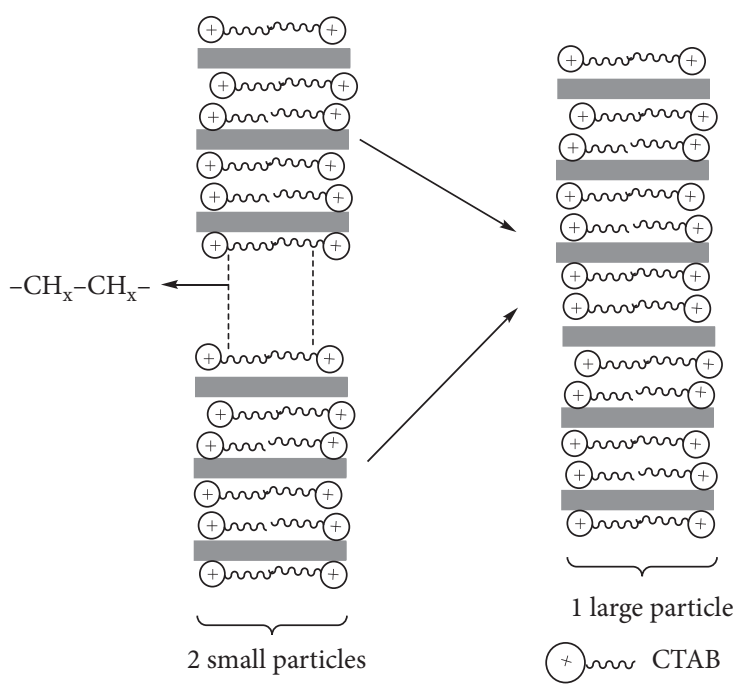

FIgURE 2: The schematic drawing for illustrating the role of CTAB.

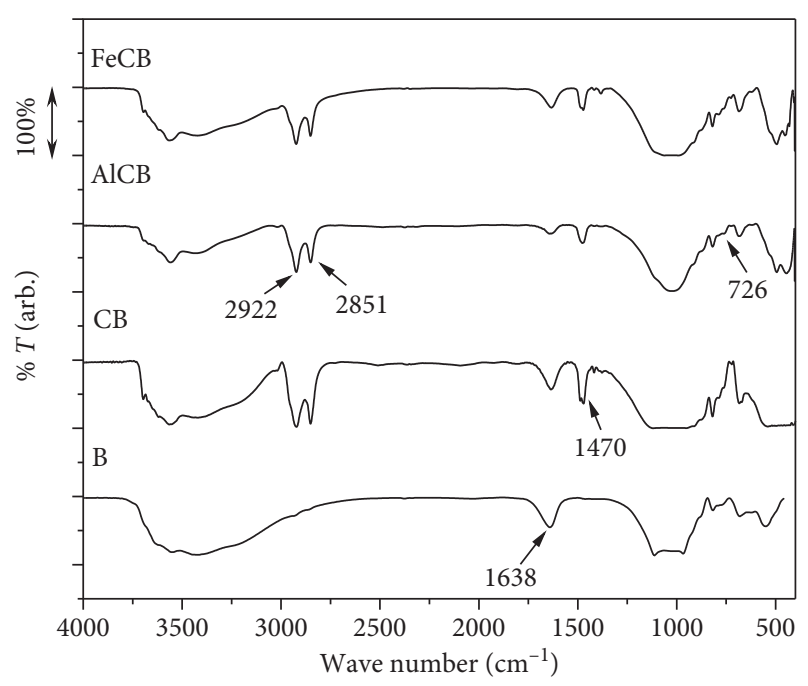

Figure 3: FT-IR spectra of $\mathrm{B}, \mathrm{CB}, \mathrm{AlCB}$, and FeCB.

explained that the large size of CTAB particles located in bentonite interlayer spaces or CTAB adsorbed at the outer surface of bentonite blocked the pathway of $\mathrm{N}_{2}$ molecules. It could be argued that CTAB intercalated into the interlayers of bentonite (filling the micropores of about 5-6 ) and $\mathrm{CTAB}$ could also be located on the outer surface (in the mesopores created between primary bentonite particles), which made the specific surface significantly reduced and the mesopores system wider. Therefore, the outside surface of bentonite would become hydrophobic and could not be able to receive large-sized hydrophobic molecules. Compared with $\mathrm{B}$, the $\mathrm{AlCB}$ and $\mathrm{FeCB}$ samples had the larger specific surface area, suggesting that a part of the large organic cations was replaced by the inorganic cations of smaller size. In addition, it was found that the organic-inorganic bentonite samples contained no micropores or the windows of micropores were closed, so $\mathrm{N}_{2}$ molecules could not be able to access these spaces.

\subsection{Adsorption Studies}

3.2.1. Effect of $p H$. The $\mathrm{pH}$ is one of the most important factors affecting the adsorption capacity of phenol red on modified bentonite surface. The change of $\mathrm{pH}$ affects the dissociation of functional groups on the adsorbent and then affects its affinity to adsorbate. The $\mathrm{pH}$ effect on the adsorption of phenol red on the modified bentonites is shown in Figure 7.

As shown in Figure 7, the phenol red absorption on the $\mathrm{CB}$ sample was generally less affected by $\mathrm{pH}$ than that on the AlCB and FeCB samples. The amount of the adsorbed phenol red increased slightly in the range of $\mathrm{pH}$ from 2.0 to 3.0 and then decreased slightly from 3.0 to 9.0. For AlCB and FeCB samples, the red phenol absorption had a similar trend: a maximum absorption at $\mathrm{pH} 3.0$ and a remarkable decrease of adsorption capacity were observed when increasing $\mathrm{pH}$ from 3.0 to 9.0 . This could be explained by electrostatic interactions between phenol red and adsorbents. In aqueous solution, phenol red exists in different forms of $\mathrm{H}_{2}^{+} \mathrm{PS}^{-}, \mathrm{HPS}^{-}$, and $\mathrm{PS}^{2-}$ depending on the $\mathrm{pH}$ of the solution (Scheme 1).

Thus, in any environment, the red phenol also contains a group of sulfate with a negative charge. The $\mathrm{pH}_{\mathrm{PZC}}$ of $\mathrm{CB}, \mathrm{AlCB}$, and $\mathrm{FeCB}$ samples determined by the $\mathrm{pH}$ drift method was found to be 7.1, 6.3, and 5.8, respectively, so at $\mathrm{pH}<\mathrm{pH}_{\mathrm{PZC}}$, the modified bentonite surface was positively charged which was favorable for the adsorption of phenol red by electrostatic interaction. However, at a $\mathrm{pH}>\mathrm{pH}_{\mathrm{PZC}}$, the modified clay surface was negatively charged, causing a repulsion force between bentonite surface and the phenol red as well as $\mathrm{OH}^{-}$anion (hydroxyl ions and phenol red could compete for adsorption at high $\mathrm{pH}$ ), resulting in the decrease of the adsorption capacity when $\mathrm{pH}$ increased. In addition, due to the presence of CTAB in bentonite, phenol red absorption on modified bentonite was also conducted by ligand exchange, but this process did not involve a change 


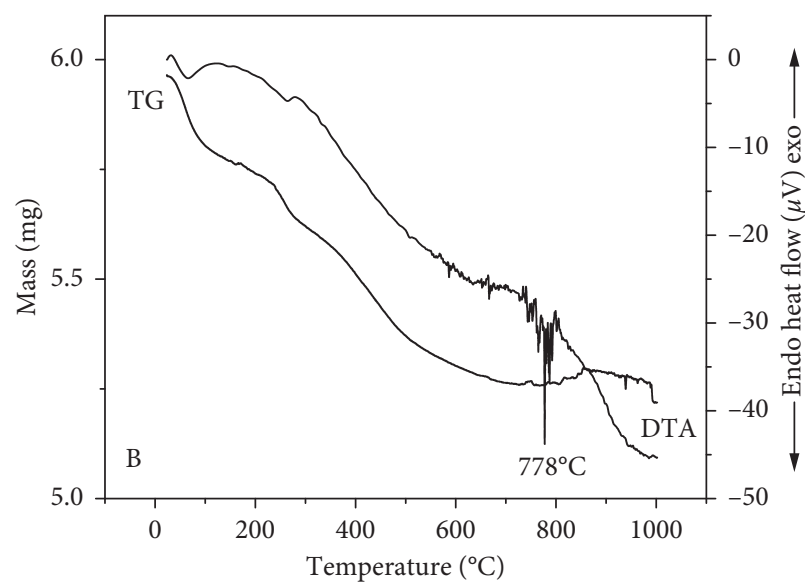

(a)

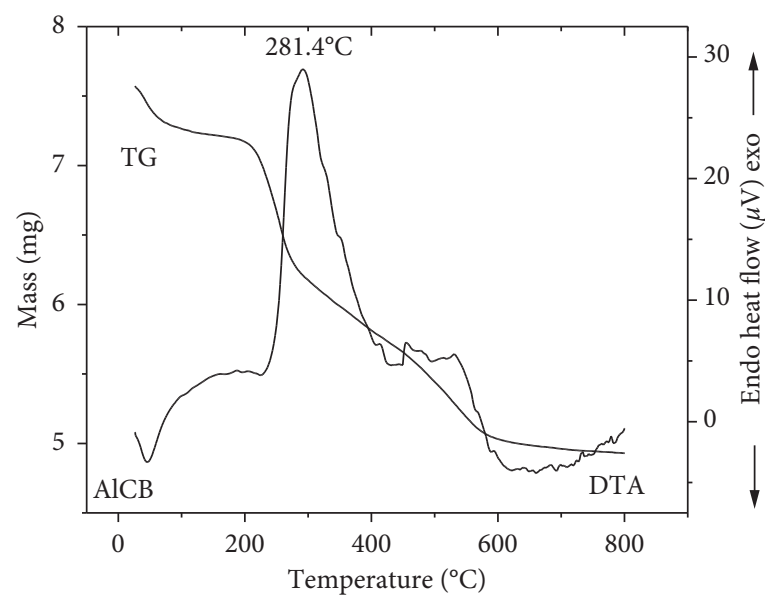

(c)

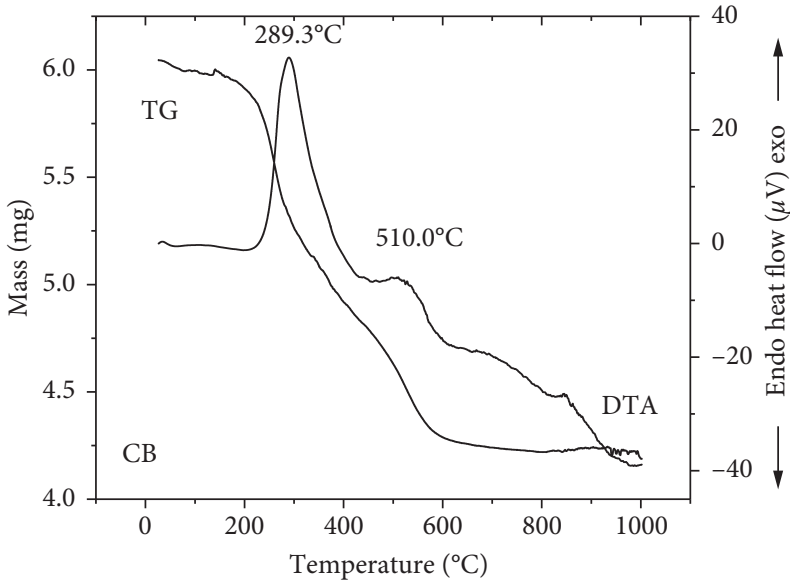

(b)

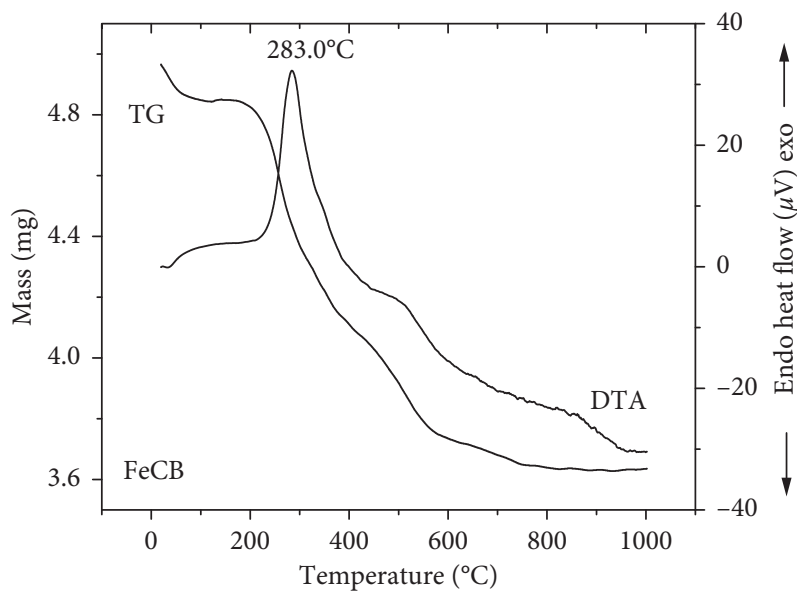

(d)

Figure 4: TG and DTA curves of (a) B, (b) CB, (c) AlCB, and (d) FeCB.

in $\mathrm{pH}$ (this was verified experimentally): $\mathrm{CTA}^{+}-\mathrm{Br}^{-}+$ $\mathrm{HPS}^{-} \longrightarrow \mathrm{CTA}^{+}-\mathrm{HPS}^{-}+\mathrm{Br}^{-}$

In short, the reduction of phenol red adsorption over the $\mathrm{pH}$ range could be related to two possible mechanisms: electrostatic interaction and chemical reaction between modified bentonites and phenol red. From this result, the optimum $\mathrm{pH} 3.0$ for red phenol adsorption on modified bentonite samples was chosen for further studies.

3.2.2. Adsorption Kinetics. The kinetics data obtained at different temperatures using the pseudo-first and pseudosecond kinetic models are presented in Figures 8-10.

Parameters of the pseudo-first-order and pseudo-second-order kinetic model are listed in Table 2.

Based on the value of $R^{2}$ and the difference of $q_{e}$ calculated by two models compared with the empirical $q_{e}$, it was found that pseudo-second-order model showed better goodness of fit to the experimental data than the pseudofirst-order model. Similar results were reported for the phenol red on bottom ash and deoiled soya [12]. From Table 2, it can be seen that the $k_{2}$ value increased with the temperature for all three samples (CB: $0.778 .10^{-3}-1.524 .10^{-3}$ $\mathrm{g} \cdot \mathrm{mg}^{-1} \cdot \mathrm{min}^{-1}, \quad \mathrm{AlCB}: \quad 0.73 .10^{-3}-2.53 .10^{-3} \mathrm{~g} \cdot \mathrm{mg}^{-1} \cdot \mathrm{min}^{-1}$, FeCB: $\left.4.1 .10^{-3}-6.53 .10^{-3} \mathrm{~g} \cdot \mathrm{mg}^{-1} \cdot \mathrm{min}^{-1}\right)$. Under the same conditions, the phenol red adsorption rate on FeCB sample was faster than that on other samples. The interesting result of the simultaneous insertion of organic and inorganic species into bentonite was that the adsorption capacity of phenol red was reduced, but the adsorption rate increased compared to those of bentonite intercalated by organic cations. The phenol red has a molecular size of about $15 \AA$, so the phenol red absorption had to occur in the mesopores of materials ( several hundred $\AA$ ) and could not occur between the smectite layers $(\sim 5-10 \AA)$. The values of $k_{2}$ of all modified bentonite samples were the same order $\left(10^{-3}\right)$, which suggested that the phenol red adsorbed mainly at the outer surface and in the capillaries created between the primary particles.

The values of rate constants from the pseudo-secondorder model can be used to calculate the activation energy of the sorption process by the Arrhenius equation. Figure 11 depicts the Arrhenius plots of phenol red adsorption onto $\mathrm{CB}, \mathrm{AlCB}$, and $\mathrm{FeCB}$. 


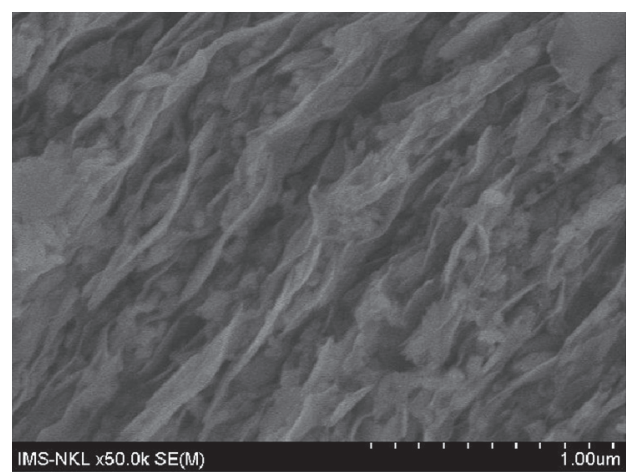

(a)

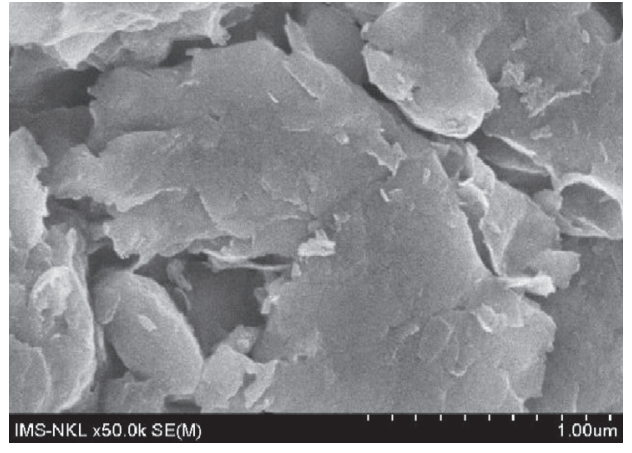

(c)

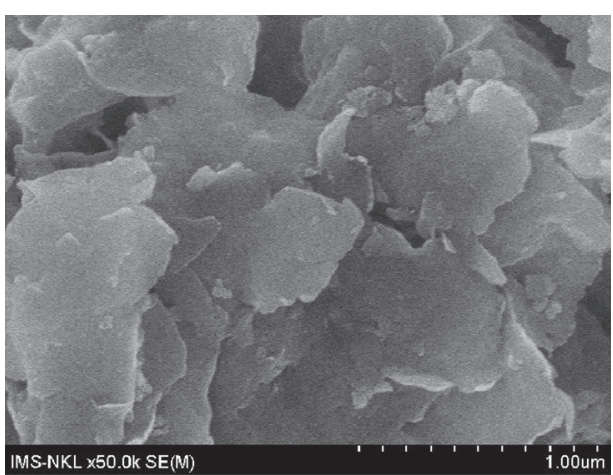

(b)

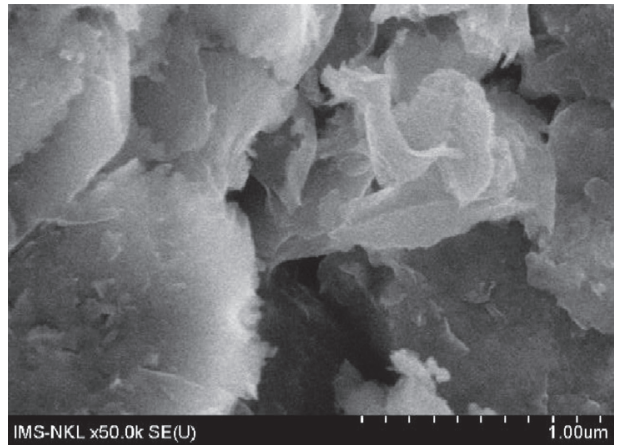

(d)

Figure 5: SEM micrographs of B (a), CB (b), AlCB (c), and FeCB (d).

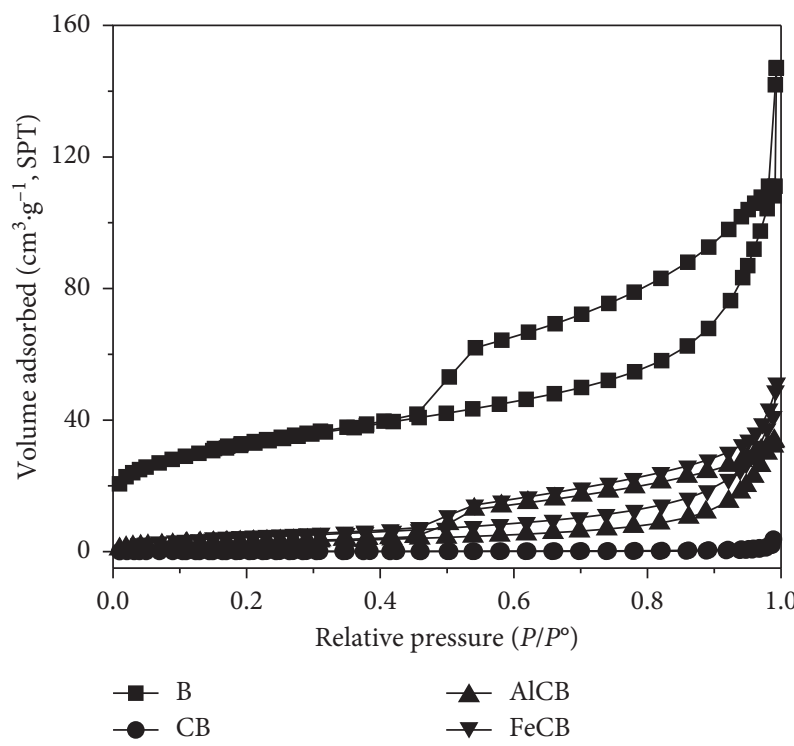

FIgUre 6: $\mathrm{N}_{2}$ adsorption-desorption isotherms of $\mathrm{B} \mathrm{CB}, \mathrm{AlCB}$, and FeCB.

TABLE 1: Textural parameters of $\mathrm{B} \mathrm{CB}, \mathrm{AlCB}$, and FeCB samples.

\begin{tabular}{lcccc}
\hline Sample & $\mathrm{S}_{\mathrm{BET}}\left(\mathrm{m}^{2} \cdot \mathrm{g}^{-1}\right)$ & $S_{\text {micro }}\left(\mathrm{m}^{2} \cdot \mathrm{g}^{-1}\right)$ & $S_{\text {ext }}\left(\mathrm{m}^{2} \cdot \mathrm{g}^{-1}\right)$ & $\mathrm{V}_{\text {total }}\left(\mathrm{cm}^{3} \cdot \mathrm{g}^{-1}\right)$ \\
\hline $\mathrm{B}$ & 114.44 & 44.72 & 69.72 & 0.187 \\
$\mathrm{CB}$ & 0.25 & 0.22 & 0.03 & 0.002 \\
$\mathrm{AlCB}$ & 10.07 & - & - & 0.110 \\
FeCB & 16.56 & - & - & 0.072 \\
\hline
\end{tabular}




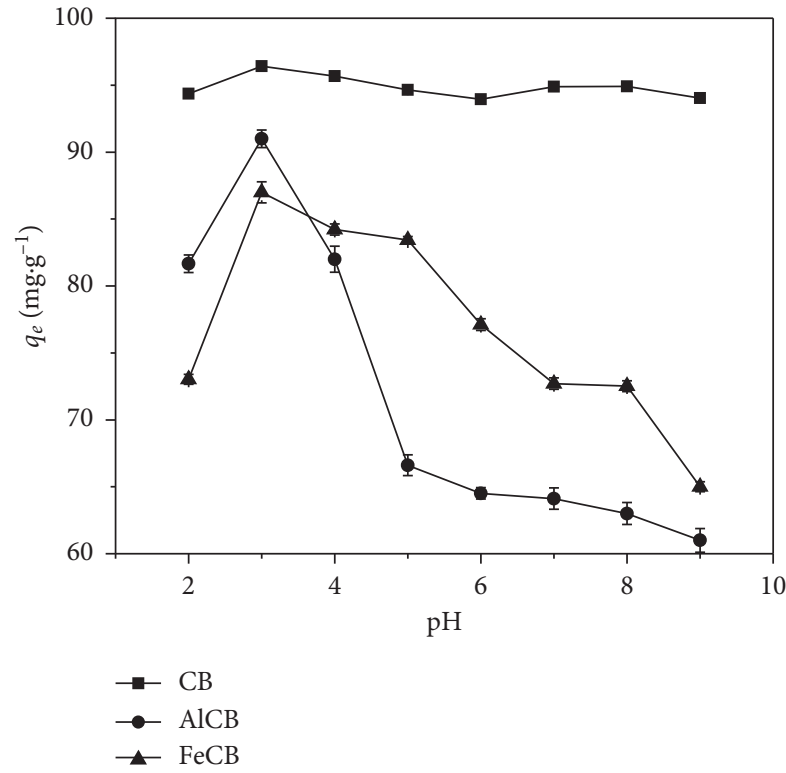

Figure 7: Effect of $\mathrm{pH}$ on the adsorption uptake of phenol red onto CB, AlCB, and FeCB samples $\left(C_{\mathrm{o}}\right.$ (phenol red) $=100 \mathrm{mg} \mathrm{L}-1, T=303$, $\mathrm{K} m=0.05 \mathrm{~g} t=6 \mathrm{~h}$ ).<smiles></smiles>

$\mathrm{H}_{2}{ }^{+} \mathrm{PS}^{-}$<smiles>O=C1C=CC(=C(c2ccc(O)cc2)c2ccccc2[NH+]([O-])c2ccc(O)cc2)C=C1</smiles>

PS $^{2-}$

Scheme 1: Different forms of phenol red.

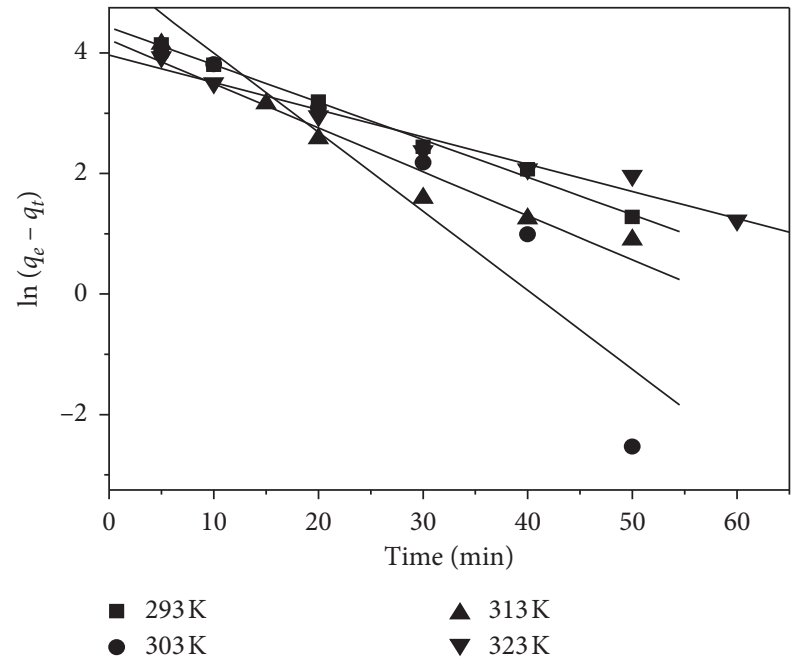

(a)

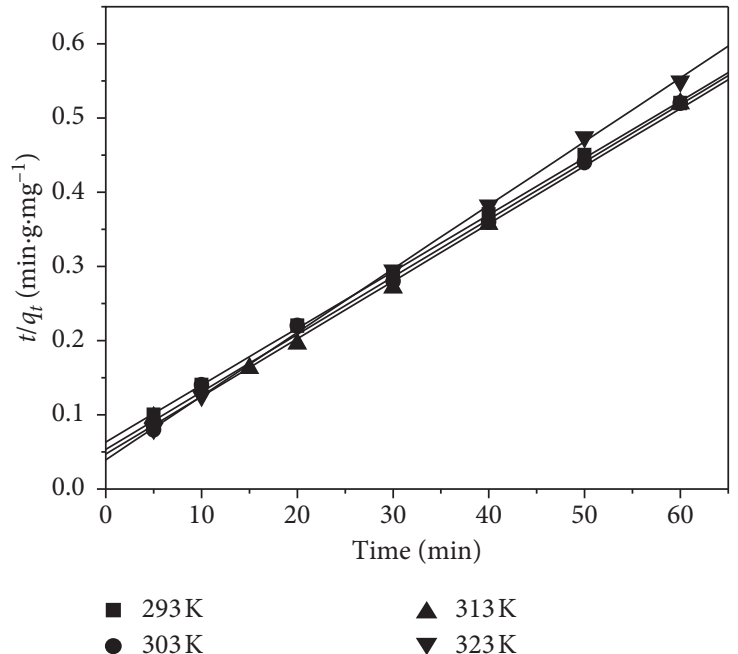

(b)

FIgURE 8: (a) The pseudo-first-order kinetic model and (b) pseudo-second-order kinetic model of phenol red adsorption by CB at different temperatures $\left(C_{\mathrm{o}}\right.$ (phenol red) $\left.=100 \mathrm{mg} \mathrm{L}^{-1}, \mathrm{pH} 3.0, m=0.2 \mathrm{~g}\right)$. 


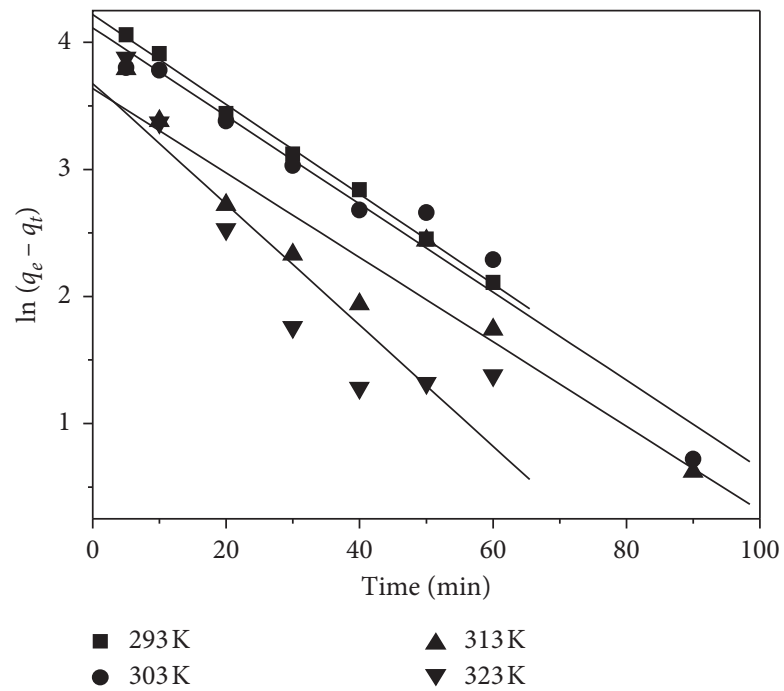

(a)

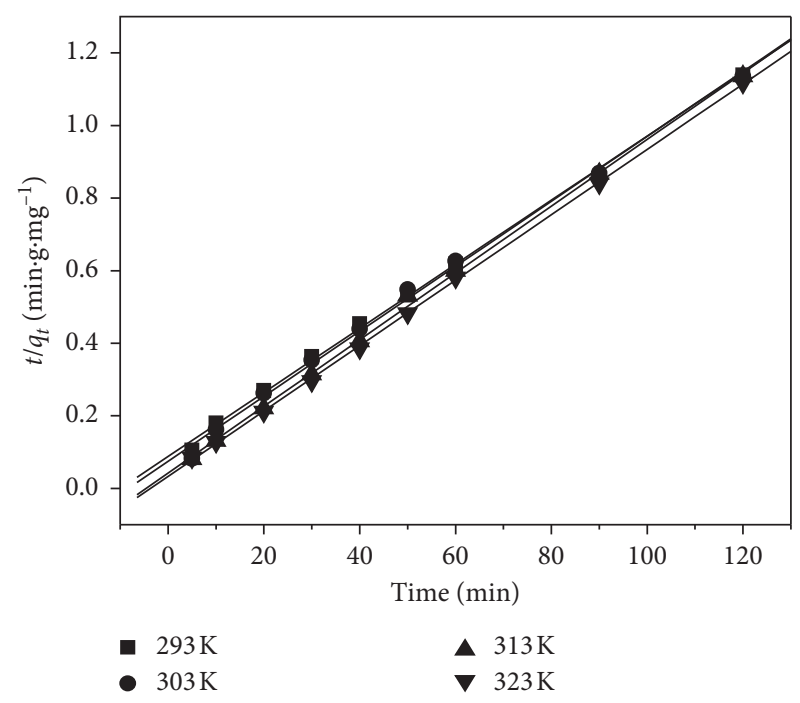

(b)

Figure 9: (a) The pseudo-first-order kinetic model and (b) pseudo-second-order kinetic model of phenol red adsorption by AlCB at different temperatures $\left(C_{o(\text { phenol red })}=100 \mathrm{mg} \mathrm{L}^{-1}, \mathrm{pH} 3.0, m=0.2 \mathrm{~g}\right)$.

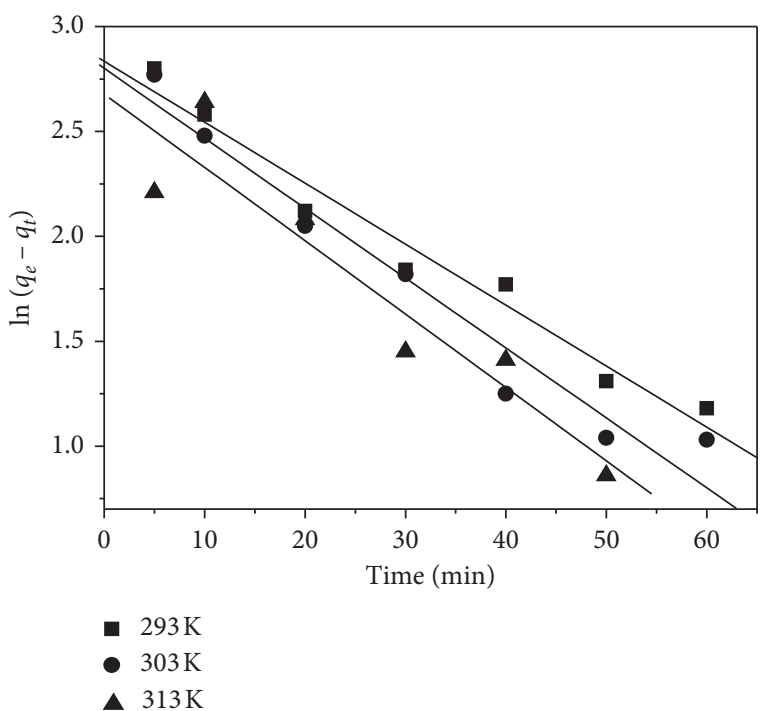

(a)

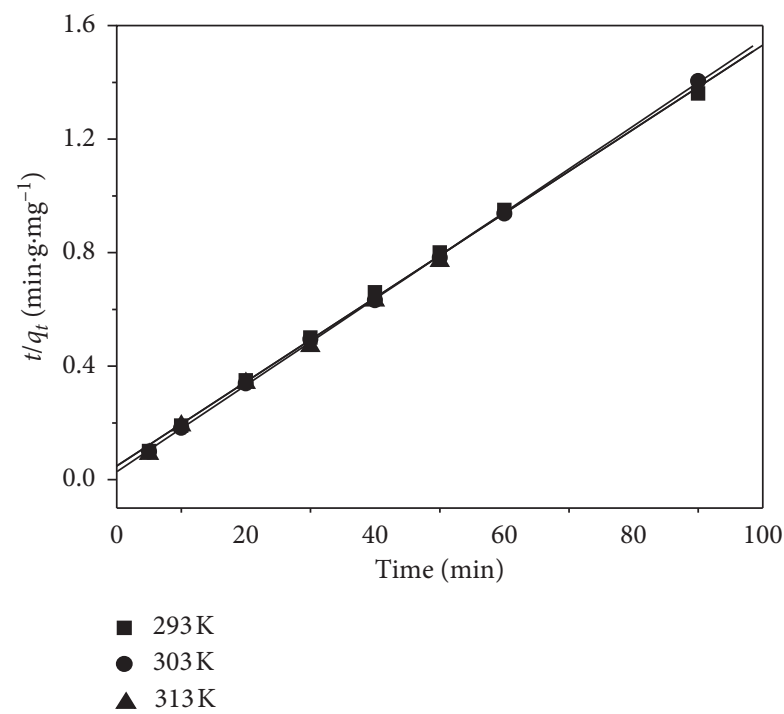

(b)

Figure 10: (a) The pseudo-first-order kinetic model and (b) pseudo-second-order kinetic model of phenol red adsorption by FeCB at

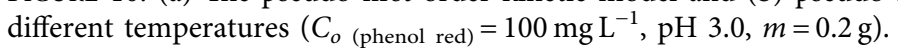

The values of the activation energy were found to be $17.82 \mathrm{~kJ} \cdot \mathrm{mol}^{-1}, 33.87 \mathrm{~kJ} \cdot \mathrm{mol}^{-1}$, and $17.52 \mathrm{~kJ} \cdot \mathrm{mol}^{-1}$ for the phenol red adsorption onto $\mathrm{CB}, \mathrm{AlCB}$, and $\mathrm{FeCB}$, respectively. The magnitude of activation energy can give information if the adsorption process is physical or chemical. The value of $E_{a}$ was not large, indicating that phenol red adsorption on the three investigated materials was mainly physical adsorption (due to electrostatic interaction) as analyzed above. Comparing the $E_{a}$ values of phenol red adsorption on the three materials, the $E_{a}$ value of $\mathrm{AlCB}$ material was the highest. This suggested that phenol red adsorption on $\mathrm{CB}$ and $\mathrm{FeCB}$ materials was more advantageous in terms of energy than that on AlCB material.

3.2.3. Adsorption Isotherms. The mechanism of adsorption reactions could be determined by evaluating the equilibrium data obtained from the experiments. The experimental data plotted with the Langmuir, Freundlich, and Dubinin-Radushkevich isotherm models are shown in Figures 12-14. The estimated adsorption constants with the correlation coefficient obtained from the isotherms are listed in Table 3. 
TABLE 2: Parameters of pseudo-first-order and pseudo-second-order kinetic model of phenol red adsorption by $\mathrm{CB}, \mathrm{AlCB}$, and FeCB at different temperatures.

\begin{tabular}{lccccccc}
\hline \multirow{2}{*}{ Adsorbents } & $T(\mathrm{~K})$ & $q_{\mathrm{e}}$ (experimental) $\left(\mathrm{mg}^{-1}\right)$ & \multicolumn{2}{c}{ First-order kinetic model } & \multicolumn{3}{c}{ Second-order kinetic model } \\
& & & $k_{1}\left(\mathrm{~min}^{-1}\right)$ & $q_{e}(\mathrm{cal})\left(\mathrm{mg}^{-1}\right)$ & $R^{2}$ & $k_{2}\left(\mathrm{~g} \cdot \mathrm{mg}^{-1} \cdot \mathrm{min}^{-1}\right)$ & $\mathrm{qe}(\mathrm{cal})(\mathrm{mg} \cdot \mathrm{g}-1)$ \\
$R^{2}$
\end{tabular}

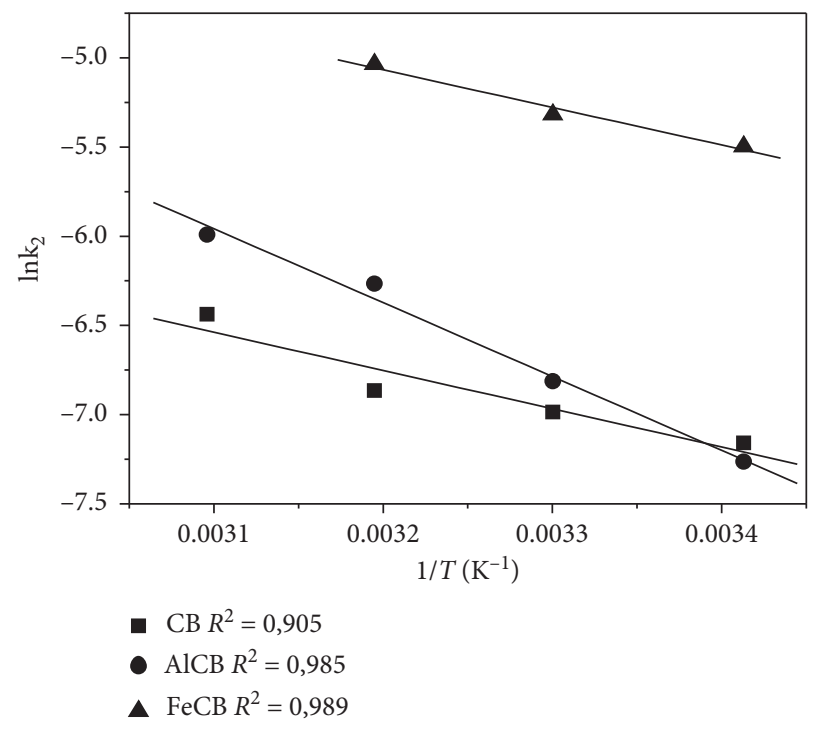

FIGURE 11: Arrhenius plots of phenol red adsorption onto $\mathrm{CB}$, AlCB, and FeCB.

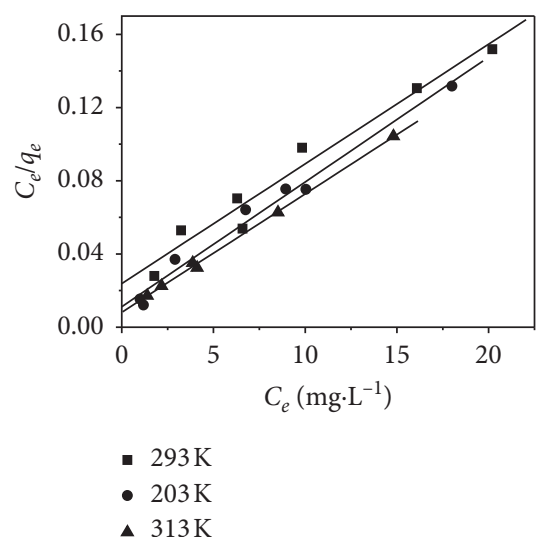

(a)

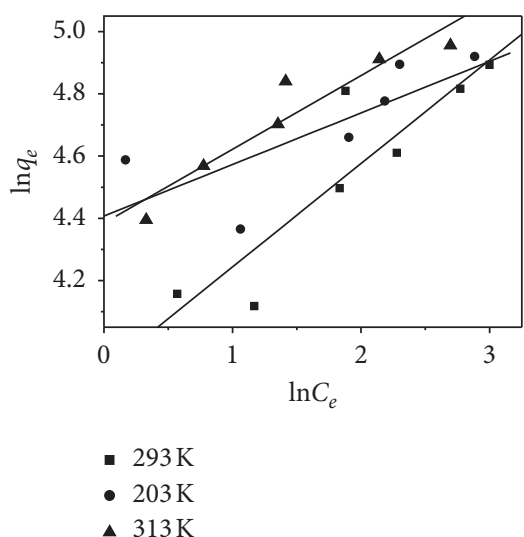

(b)

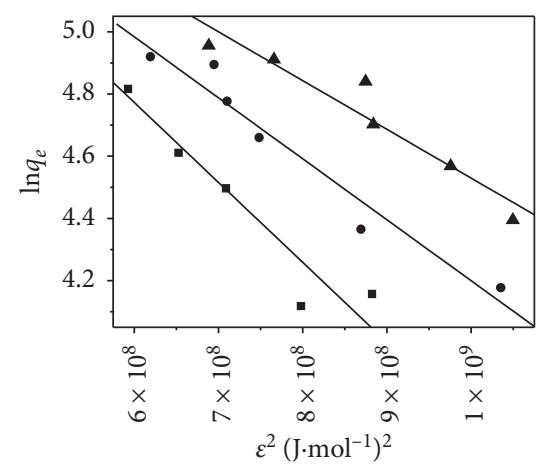

- $293 \mathrm{~K}$

- $203 \mathrm{~K}$

$\Delta 313 \mathrm{~K}$

(c)

Figure 12: (a) Plots of Langmuir, (b) Freundlich, and (c) Dubinin-Radushkevich isotherms in linear form for the adsorption of phenol red onto $\mathrm{CB}$ at different temperatures. 


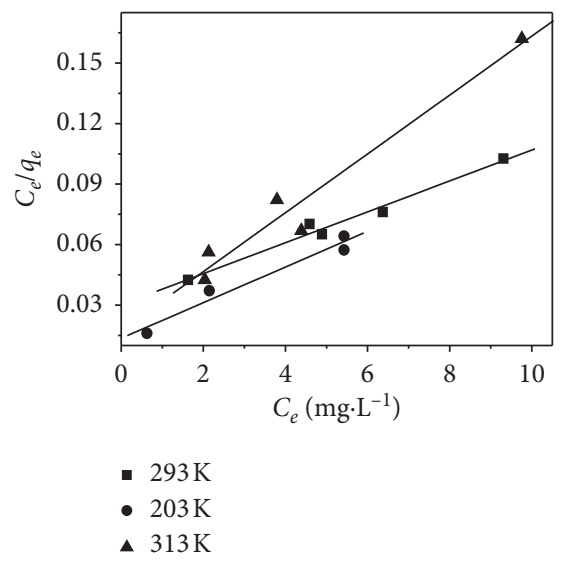

(a)

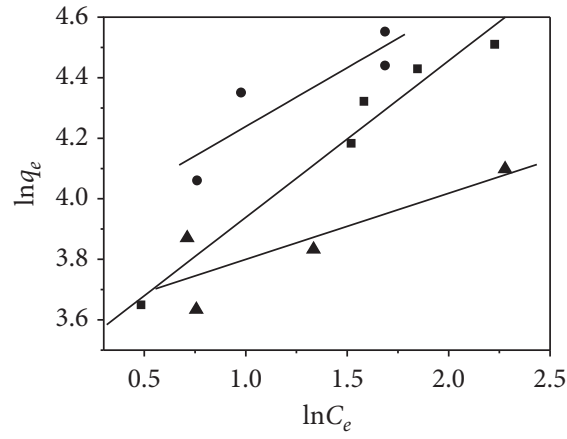

- $293 \mathrm{~K}$

- $203 \mathrm{~K}$

- $313 \mathrm{~K}$

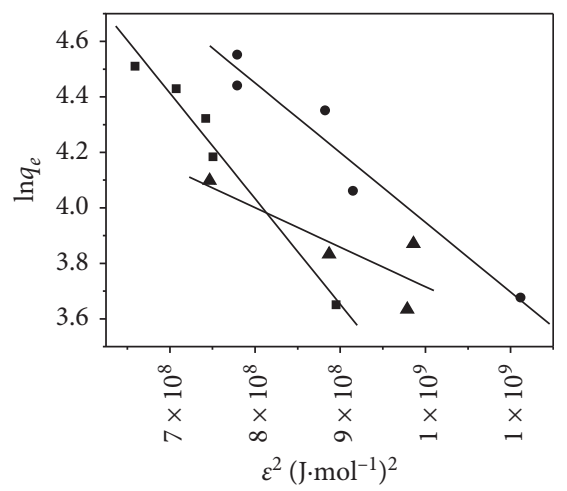

- $293 \mathrm{~K}$

- $203 \mathrm{~K}$

- $313 \mathrm{~K}$

(b)

(c)

Figure 13: (a) Plots of Langmuir, (b) Freundlich, and (c) Dubinin-Radushkevich isotherms in linear form for the adsorption of phenol red onto AlCB at different temperatures.

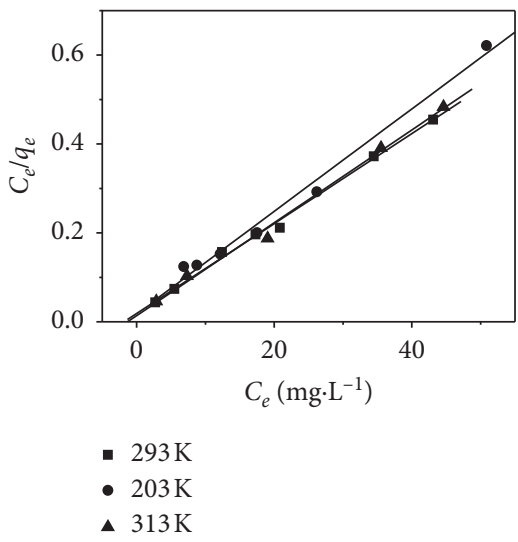

(a)

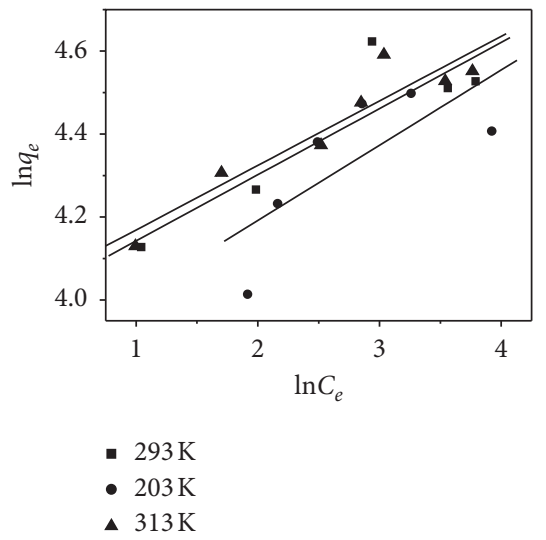

(b)

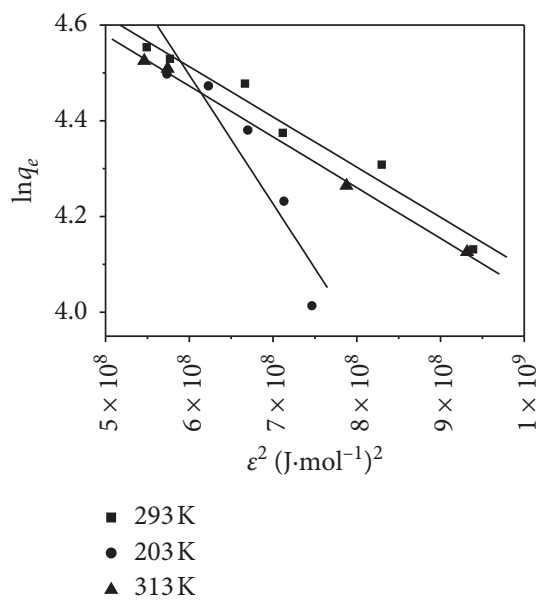

(c)

Figure 14: (a) Plots of Langmuir, (b) Freundlich, and (c) Dubinin-Radushkevich isotherms in linear form for the adsorption of phenol red onto $\mathrm{FeCB}$ at different temperatures.

In terms of the correlation coefficient $R^{2}$ values, the experimental data could be well fitted to the Langmuir isotherm model rather than the Freundlich and D-R models at all investigated temperatures, indicating that the adsorption process occurred on the surface of modified bentonites. The calculated values of $R_{L}$ were found to be between 0 and 1 , indicating that the adsorption of phenol red onto $\mathrm{CB}, \mathrm{AlCB}$, and $\mathrm{FeCB}$ samples was favorable. At the same conditions, the value of $q_{\max }$ calculated from the Langmuir equation of all samples decreases in the order of $\mathrm{CB}$, $\mathrm{AlCB}$, and $\mathrm{FeCB}$ in the temperature range $20-40^{\circ} \mathrm{C}$. The maximum phenol red adsorption capacities $\left(q_{\max }\right)$ at $30^{\circ} \mathrm{C}$ (room temperature) are $166.7 \mathrm{mg} \cdot \mathrm{g}^{-1}$ for $\mathrm{CB}, 125.0 \mathrm{mg} \cdot \mathrm{g}^{-1}$ for $\mathrm{AlCB}$, and $100 \mathrm{mg} \cdot \mathrm{g}^{-1}$ for $\mathrm{FeCB}$. It is known that the specific surface area of CB was smaller but its adsorption capacity is higher than that of other two materials. This suggested that the presence of hydroxy-Al and hydroxy-Fe cations in CTAB-bentonite reduced the phenol red adsorption capacity of this material. In addition, the $K_{L}$ value at the same temperature on three investigated materials was different illustrating that active sites on these three materials were different. In comparison with previous studies $[25,26]$, the phenol adsorption capacity of organobentonite was higher than phenol red adsorption capacity of CTAB-bentonite in this study; this could be explained by the fact that the size of phenol was smaller than that of phenol red, so it was more easily diffused into the capillary than phenol red. However, it is notable that the present adsorbents exhibit much higher adsorption capacity compared with those of adsorbents for phenol red reported previously, suggesting that modified 
TABle 3: The parameters of isotherm models in linear form for the adsorption of phenol red onto the modified bentonite.

\begin{tabular}{|c|c|c|c|c|c|c|c|c|c|}
\hline \multicolumn{10}{|c|}{$\mathrm{CB}$} \\
\hline \multirow{2}{*}{$T(\mathrm{~K})$} & \multicolumn{3}{|c|}{ Langmuir model } & \multicolumn{4}{|c|}{ Freundlich model } & \multicolumn{2}{|c|}{ D-R model } \\
\hline & $q_{m}\left(\mathrm{mg} \cdot \mathrm{g}^{-1}\right)$ & $K_{L}\left(\mathrm{~L} \cdot \mathrm{mg}^{-1}\right)$ & $R^{2}$ & $R_{L}$ & $K_{F}\left(\mathrm{mg} \cdot \mathrm{g}^{-1}\right)$ & $n$ & $R^{2}$ & $E\left(\mathrm{~kJ} \cdot \mathrm{mol}^{-1}\right)$ & $R^{2}$ \\
\hline 293 & 156.3 & 0.185 & 0.964 & $0.211-0.752$ & 49.95 & 3.01 & 0.808 & 13.95 & 0.932 \\
\hline 303 & 166.7 & 0.278 & 0.983 & $0.167-0.782$ & 93.04 & 8.19 & 0.784 & 15.97 & 0.952 \\
\hline 313 & 169.4 & 0.625 & 0.998 & $0.098-0.535$ & 80.16 & 4.22 & 0.897 & 17.86 & 0.913 \\
\hline \multicolumn{10}{|l|}{$\mathrm{AlCB}$} \\
\hline$T(\mathrm{~K})$ & \multicolumn{3}{|c|}{ Langmuir model } & \multicolumn{3}{|c|}{ Freundlich model } & \multicolumn{3}{|c|}{ D-R model } \\
\hline $1(\mathrm{~K})$ & $q_{m}\left(\mathrm{mg} \cdot \mathrm{g}^{-1}\right)$ & $K_{L}\left(\mathrm{~L} \cdot \mathrm{mg}^{-1}\right)$ & $R^{2}$ & $R_{L}$ & $K_{F}\left(\mathrm{mg} \cdot \mathrm{g}^{-1}\right)$ & $n$ & $R^{2}$ & $E\left(\mathrm{~kJ} \cdot \mathrm{mol}^{-1}\right)$ & $R^{2}$ \\
\hline 293 & 71.4 & 0.23 & 0.979 & $0.316-0.725$ & 30.60 & 1.93 & 0.969 & 11.46 & 0.974 \\
\hline 303 & 125.0 & 0.62 & 0.959 & $0.017-0.040$ & 46.99 & 2.58 & 0.787 & 14.11 & 0.943 \\
\hline 313 & 142.9 & 0.82 & 0.956 & $0.111-0.373$ & 35.91 & 4.59 & 0.701 & 18.74 & 0.695 \\
\hline \multicolumn{10}{|l|}{$\mathrm{FeCB}$} \\
\hline$T(\mathrm{~K})$ & \multicolumn{3}{|c|}{ Langmuir model } & \multicolumn{3}{|c|}{ Freundlich model } & \multicolumn{3}{|c|}{ D-R model } \\
\hline 1 (N) & $q_{m}\left(\mathrm{mg} \cdot \mathrm{g}^{-1}\right)$ & $K_{L}\left(\mathrm{~L} \cdot \mathrm{mg}^{-1}\right)$ & $R^{2}$ & $R_{L}$ & $K_{F}\left(\mathrm{mg} \cdot \mathrm{g}^{-1}\right)$ & $n$ & $R^{2}$ & $E\left(\mathrm{~kJ} \cdot \mathrm{mol}^{-1}\right)$ & $R^{2}$ \\
\hline 293 & 90.9 & 0.77 & 0.996 & $0.073-0.191$ & 55.31 & 6.45 & 0.885 & 21.83 & 0.969 \\
\hline 303 & 100.0 & 0.61 & 0.987 & $0.028-0.313$ & 31.12 & 2.90 & 0.856 & 13.62 & 0.868 \\
\hline 313 & 110.1 & 0.56 & 0.993 & $0.040-0.400$ & 51.42 & 5.46 & 0.810 & 21.71 & 0.998 \\
\hline
\end{tabular}

TABLE 4: Comparison of the adsorption capacity for various adsorbents in phenol red removal that confirm their applicability and suggest their attractive candidates for dye removal.

\begin{tabular}{lcc}
\hline Adsorbents & Maximum monolayer adsorption uptakes $\left(\mathrm{mg}^{-1}\right)$ & Ref. \\
\hline Bottom ash & 7.4 & {$[12]$} \\
Deoiled soya & 5.3 & {$[12]$} \\
Silica-filled ENR/PVC beads & 2.6 & {$[13]$} \\
Activated charcoal & 0.04 & {$[14]$} \\
Barley husk-derived activated carbon & 6.76 & {$[34]$} \\
$\mathrm{TiO}_{2}$-NPs-ACWR & 55.6 & {$[35]$} \\
$\mathrm{PAC}$ & 43.9 & {$[36]$} \\
$\mathrm{ZnS}:$ Cu-NPs-PAC & 196.0 & {$[36]$} \\
$\mathrm{CB}$ & 166.7 & This work \\
$\mathrm{AlCB}$ & 125.0 & This work \\
FeCB & 100.0 & This work \\
\hline
\end{tabular}

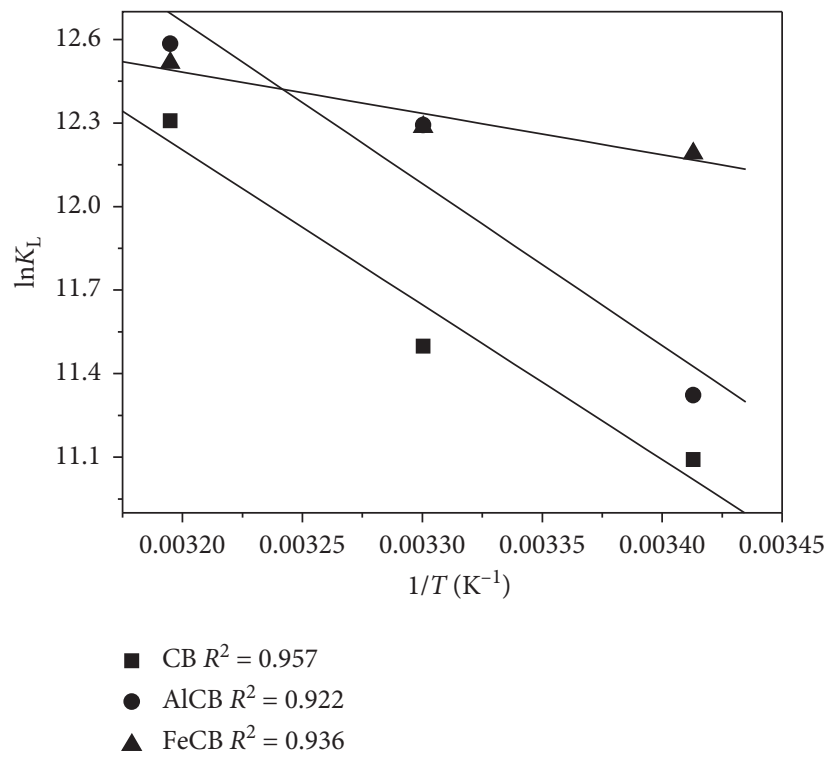

Figure 15: Plot of $\ln K_{\mathrm{L}}$ versus $1 / \mathrm{T}$. 
TABLE 5: Thermodynamic parameters for the phenol red adsorption onto $\mathrm{CB}, \mathrm{AlCB}$, and $\mathrm{FeCB}$.

\begin{tabular}{lccccccccc}
\hline$T$ & \multicolumn{3}{c}{$\mathrm{CB}$} & \multicolumn{3}{c}{$\mathrm{AlCB}$} & \multicolumn{3}{c}{$\mathrm{FeCB}$} \\
$(\mathrm{K})$ & $\begin{array}{c}\Delta G^{\circ} \\
\left(\mathrm{kJ} \cdot \mathrm{mol}^{-1}\right)\end{array}$ & $\begin{array}{c}\Delta H^{\circ} \\
\left(\mathrm{kJ} \cdot \mathrm{mol}^{-1}\right)\end{array}$ & $\begin{array}{c}\Delta S^{\circ} \\
\left(\mathrm{kJ} \cdot \mathrm{mol}^{-1} \cdot \mathrm{K}^{-1}\right)\end{array}$ & $\begin{array}{c}\Delta G^{\circ} \\
\left(\mathrm{kJ} \cdot \mathrm{mol}^{-1}\right)\end{array}$ & $\begin{array}{c}\Delta H^{\circ} \\
\left(\mathrm{kJ} \cdot \mathrm{mol}^{-1}\right)\end{array}$ & $\begin{array}{c}\Delta S^{\circ} \\
\left(\mathrm{kJ} \cdot \mathrm{mol}^{-1} \cdot \mathrm{K}^{-1}\right)\end{array}$ & $\begin{array}{c}\Delta G^{\circ} \\
\left(\mathrm{kJ} \cdot \mathrm{mol}^{-1}\right)\end{array}$ & $\begin{array}{c}\Delta H^{\circ} \\
\left(\mathrm{kJ} \cdot \mathrm{mol}^{-1}\right)\end{array}$ & $\begin{array}{c}\Delta S^{\circ} \\
\left(\mathrm{kJ} \cdot \mathrm{mol}^{-1} \cdot \mathrm{K}^{-1}\right)\end{array}$ \\
\hline 293 & -27.02 & 26.21 & 0.249 & -27.58 & 48.36 & 0.261 & -29.70 & 12.34 & 0.144 \\
303 & -28.97 & & & -30.97 & & & -30.95 & & \\
313 & -32.03 & & & -32.75 & & & -32.57 & & \\
\hline
\end{tabular}

bentonite materials are attractive candidates for dye removal. Table 4 presents the absorption capacities based on the Langmuir model of some adsorbents.

3.2.4. Thermodynamics Studies. The plot of $\ln K_{L}$ versus $1 / T$ for the determination of thermodynamic parameters is depicted in Figure 15 and the thermodynamic parameters are listed in Table 5.

The negative values of $\Delta G^{\circ}$ at different temperatures indicated the feasibility of the process and the spontaneous nature of the adsorption. The positive $\Delta H^{\circ}$ values indicated that the adsorption of phenol red onto CTAB-bentonite and $\mathrm{Fe}-$ or Al-CTAB bentonites was endothermic. Furthermore, a higher positive $\Delta S^{\circ}$ of phenol red adsorption process clearly stated that the randomness increased the modified bentonite-solution interface during adsorption. This result suggested that the phenol red adsorption onto three investigated materials was promoted by entropy than by enthalpy.

\section{Conclusions}

The synthesis of CTAB-bentonite, Al-CTAB-bentonite, and $\mathrm{Fe}-\mathrm{CTAB}$-bentonite by ion exchange was demonstrated. It was found that the CTAB, hydroxy-Al, and hydroxy-Fe cations were intercalated into the interlayer spaces of bentonite leading to an increase in the basal spacing $d_{001}$. Among the investigated materials, CTABbentonite exhibited the highest monolayer adsorption capacity at the temperature of $30^{\circ} \mathrm{C}\left(166.7 \mathrm{mg} \cdot \mathrm{g}^{-1}\right)$, followed by Al-CTAB-bentonite $\left(125.0 \mathrm{mg} \cdot \mathrm{g}^{-1}\right)$ and Fe-CTAB-bentonite $\left(100 \mathrm{mg} \cdot \mathrm{g}^{-1}\right)$. Introduction of hydroxy-Al and hydroxy-Fe cations into CTAB-bentonite clearly reduced the phenol red adsorption capacity of this material. Phenol red adsorption agreed well with the pseudo-second-order kinetic model in all the investigated temperature ranges. The results of activation energy calculation showed that phenol red adsorption on CTAB-bentonite and Fe-CTAB-bentonite materials was more advantageous in terms of energy than that on Al-CTAB-bentonite. The negative values of $\Delta G^{\circ}$ indicated that the adsorption was spontaneous whereas the positive values of $\Delta H^{\circ}$ and $\Delta S^{\circ}$ indicated the endothermic nature and increase in randomness of the adsorption, respectively. From these studies, organic and organic-inorganic bentonite materials could be used as an effective adsorbent for the removal of dyes from aqueous solution.

\section{Data Availability}

The data used to support the findings of this study are available from the corresponding author upon request.

\section{Conflicts of Interest}

The authors declare that they have no conflicts of interest.

\section{References}

[1] M. T. Yagub, T. K. Sen, S. Afroze, and H. M. Ang, "Dye and its removal from aqueous solution by adsorption: a review," Advances in Colloid and Interface Science, vol. 209, pp. 172184, 2014.

[2] A. Pirkarami and M. E. Olya, "Removal of dye from industrial wastewater with an emphasis on improving economic efficiency and degradation mechanism," Journal of Saudi Chemical Society, vol. 21, pp. 179-186, 2017.

[3] E. A. Khan, Shahjahan, and T. A. Khan, "Adsorption of methyl red on activated carbon derived from custard apple ( Annona squamosa ) fruit shell: equilibrium isotherm and kinetic studies," Journal of Molecular Liquids, vol. 249, pp. 1195-1211, 2018.

[4] T. A. Khan, E. A. Khan, and Shahjahan, "Adsorptive uptake of basic dyes from aqueous solution by novel brown linseed deoiled cake activated carbon: equilibrium isotherms and dynamics," Journal of Environmental Chemical Engineering, vol. 4, no. 3, pp. 3084-3095, 2016.

[5] M. N. Khan, O. Bashir, T. A. Khan, S. A. Al-Thabaiti, and Z. Khan, "Catalytic activity of cobalt nanoparticles for dye and 4-nitro phenol degradation: a kinetic and mechanistic study," International Journal of Chemical Kinetics, vol. 49, no. 6, pp. 438-454, 2017.

[6] M. N. Khan, O. Bashir, T. A. Khan, S. A. AL-Thabaiti, and Z. Khan, "CTAB capped synthesis of bio-conjugated silver nanoparticles and their enhanced catalytic activities," Journal of Molecular Liquids, vol. 249, pp. 1195-1211, 2018.

[7] C. K. C. Araújo, G. R. Oliveira, N. S. Fernandes et al., "Electrochemical removal of synthetic textile dyes from aqueous solutions using Ti/Pt anode: role of dye structure," Environmental Science and Pollution Research, vol. 21, no. 16, pp. 9777-9784, 2014.

[8] P. Gharbani, S. M. Tabatabaii, and A. Mehrizad, "Removal of Congo red from textile wastewater by ozonation," International Journal of Environmental Science \& Technology, vol. 5, no. 4, pp. 495-500, 2008.

[9] A. L. Ahmad, W. A. Harris, Syafiie, and O. B. Seng, "Removal of dye from wastewater of textile industry using membrane technology," Jurnal Teknologi, vol. 36, pp. 31-44, 2002.

[10] D. Bhatia, N. R. Sharma, J. Singh, and R. S. Kanwar, "Biological methods for textile dye removal from wastewater: a 
Review," Critical Reviews in Environmental Science and Technology, vol. 47, no. 19, pp. 1836-1876, 2017.

[11] V. Katheresan, J. Kansedo, and S. Y. Lau, "Efficiency of various recent wastewater dye removal methods: a review," Journal of Environmental Chemical Engineering, vol. 6, no. 4, pp. 4676-4697, 2018.

[12] A. Mittal, D. Kaur, A. Malviya, J. Mittal, and V. K. Gupta, "Adsorption studies on the removal of coloring agent phenol red from wastewater using waste materials as adsorbents," Journal of Colloid and Interface Science, vol. 337, no. 2, pp. 345-354, 2009.

[13] N. A. Abdullah, R. Othaman, I. Othaman, N. Jon, and A. Baharum, "Studies on the adsorption of phenol red dye using silica-filled ENR/PVC beads," Journal of Emerging Trends in Engineering and Applied Sciences, vol. 3, no. 5, pp. 845-850, 2012.

[14] M. J. Iqbal and M. N. Ashiq, "Adsorption of dyes from aqueous solutions on activated charcoal," Journal of Hazardous Materials, vol. 139, no. 1, pp. 57-66, 2007.

[15] A. Khenifi, B. Zohra, B. Kahina, H. Houari, and D. Zoubir, "Removal of 2, 4-DCP from wastewater by CTAB/bentonite using one-step and two-step methods: a comparative study," Chemical Engineering Journal, vol. 146, no. 3, pp. 345-354, 2009.

[16] A. Marsal, E. Bautista, I. Ribosa, R. Pons, and M. T. García, "Adsorption of polyphenols in wastewater by organo-bentonites," Applied Clay Science, vol. 44, pp. 15-155, 2009.

[17] Q. Kang, W. Zhou, Q. Li, B. Gao, J. Fan, and D. Shen, "Adsorption of anionic dyes on poly (epicholorohydrin dimethylamine) modified bentonite in single and mixed dye solutionsfied bentonite in single and mixed dye solutions," Applied Clay Science, vol. 45, no. 4, pp. 280-287, 2009.

[18] L.-g. Yan, X.-q. Shan, B. Wen, and S. Zhang, "Effect of lead on the sorption of phenol onto montmorillonites and organomontmorillonites," Journal of Colloid and Interface Science, vol. 308, no. 1, pp. 11-19, 2007.

[19] C. H. Ko, C. Fan, P. N. Chiang, M. K. Wang, and K. C. Lin, "pNitrophenol, phenol and aniline sorption by organo-clays," Journal of Hazardous Materials, vol. 149, no. 2, pp. 275-282, 2007.

[20] R.-S. Juang, S.-H. Lin, and K.-H. Tsao, "Mechanism of sorption of phenols from aqueous solutions onto surfactantmodified montmorillonite," Journal of Colloid and Interface Science, vol. 254, no. 2, pp. 234-241, 2002.

[21] D. Shen, J. Fan, W. Zhou, B. Gao, Q. Yue, and Q. Kang, "Adsorption kinetics and isotherm of anionic dyes onto organo-bentonite from single and multisolute systems," Journal of Hazardous Materials, vol. 172, no. 1, pp. 99-107, 2009.

[22] B. Zohra, K. Aicha, S. Fatima, B. Nourredine, and D. Zoubir, "Adsorption of Direct Red 2 on bentonite modified by cetyltrimethylammonium bromidefied by cetyltrimethylammonium bromide," Chemical Engineering Journal, vol. 136, no. 2-3, pp. 295-305, 2008.

[23] T. Wang, J. Su, X. Jin, Z. Chen, M. Megharaj, and R. Naidu, "Functional clay supported bimetallic nZVI/Pd nanoparticles used for removal of methyl orange from aqueous solution," Journal of Hazardous Materials, vol. 262, pp. 819-825, 2013.

[24] Y. Shu, L. Li, Q. Zhang, and H. Wu, "Equilibrium, kinetics and thermodynamic studies for sorption of chlorobenzenes on CTMAB modified bentonite and kaolinite," Journal of Hazardous Materials, vol. 173, no. 1-3, pp. 47-53, 2010.

[25] H. B. Senturk, D. Ozdes, A. Gundogdu, C. Duran, and M. Soylak, "Removal of phenol from aqueous solutions by adsorption onto organomodified Tirebolu bentonite: equilibrium, kinetic and thermodynamic study," Journal of Hazardous Materials, vol. 172, no. 1, pp. 353-362, 2009.

[26] R. Ocampo-Perez, R. Leyva-Ramos, J. Mendoza-Barron, and R. M. Guerrero-Coronado, "Adsorption rate of phenol from aqueous solution onto organobentonite: surface diffusion and kinetic models," Journal of Colloid and Interface Science, vol. 364, no. 1, pp. 195-204, 2011.

[27] T. DongShen, Z. ChunHui, L. Yan, Y. HongYan, Z. GuoFei, and Y. WeiHua, "Adsorption of acid red G dye on octadecyl trimethylammonium montmorillonite," Applied Clay Science, vol. 50, pp. 427-431, 2010.

[28] N. Ayawei, A. N. Ebelegi, and D. Wankasi, "Modelling and interpretation of adsorption isotherms," Journal of Chemistry, vol. 2017, Article ID 3039817, 11 pages, 2017.

[29] Z. Hu, G. He, Y. Liu, C. Dong, X. Wu, and W. Zhao, "Effects of surfactant concentration on alkyl chain arrangements in dry and swollen organic montmorillonite," Applied Clay Science, vol. 75-76, pp. 134-140, 2013.

[30] P. Wu, W. Wu, S. Li et al., "Removal of $\mathrm{Cd} 2+$ from aqueous solution by adsorption using Fe-montmorillonite," Journal of Hazardous Materials, vol. 169, no. 1-3, pp. 824-830, 2009.

[31] K. Nejati and Z. Rezvani, "Synthesis and characterisation of nanohybrids of olsalazine-intercalated Al-Mg layered double hydroxide," Journal of Experimental Nanoscience, vol. 7, no. 4, pp. $412-425,2012$.

[32] V. Stubican and R. Roy, "A new approach to the assignment of IR absorption bands in layer silicates," Z Kristtallogr, vol. 115, pp. 200-214, 1961.

[33] W. Xue, H. He, J. Zhu, and P. Yuan, "FTIR investigation of CTAB-Al-montmorillonite complexes," Spectrochimica Acta Part A: Molecular and Biomolecular Spectroscopy, vol. 67, no. 3-4, pp. 1030-1036, 2007.

[34] N. Alebachew, O. P. Yadav, and Lokesh, "Removal of phenol red dye from contaminated water using Barley (Hordeum vulgare L.) husk-derived activated carbon," Science International, vol. 5, pp. 7-16, 2017.

[35] N. Masoudian, M. Rajabi, and M. Ghaedi, "Titanium oxide nanoparticles loaded onto activated carbon prepared from bio-waste watermelon rind for the efficient ultrasonic-assisted adsorption of Congo red and phenol red dyes from wastewaters," Polyhedron, vol. 73, pp. 105-114, 2019.

[36] N. Masoudian, M. Rajabi, M. Ghaedi, and A. Asghari, "Highly efficient adsorption of naphthol green $B$ and phenol red dye by combination of ultrasound wave and copper doped zinc sulfide nanoparticles loaded on pistachio nut shell," Applied Organometallic Chemistry, vol. 32, Article ID e4369, 2018. 